\title{
ERASMO E LUTERO: O LIVRE ARBÍTRIO DA VONTADE HUMANA
}

\section{Erasmus and Luther: free will of humanity}

\author{
Sidnei Francisco do Nascimento ${ }^{1}$
}

\section{Resumo}

Erasmo de Roterdam e Martinho Lutero discutem acerca da noção de livre arbítrio da vontade humana. A vontade racional é livre? Ou a natureza humana não possui autonomia e sua vontade depende única e exclusivamente da vontade de Deus? A crise religiosa que se instalara no século XVI nos remete à discussão da reforma da Igreja Oficial de Roma, e à ruptura com a cultura elaborada pelos primeiros padres da Igreja no final da Antigüidade. O mundo religioso se refaz por meio de diálogos e conflitos entre a ortodoxia e os dissidentes. O Humanismo Cristão e a Reforma, Erasmo e Lutero estão de acordo sobre um ponto: "O céu não está à venda". Mas o que parece, à primeira vista, aproximálos, distancia-os cada vez mais, quando a questão se volta para 0 descaso da Reforma quanto à tradição da Igreja. Erasmo retoma a Filosofia Patrística e aceita, compreendendo ou não, o que a Igreja elaborou por tantos séculos de cultura religiosa, ao contrário de seu adversário. Sendo assim, a discussão sobre o livre arbítrio da vontade conduz, e é ao mesmo tempo conduzida, à cisão do dogma cristão, à separação entre Filosofia e Teologia e o início da modernidade.

Palavras-chave: Erasmo; Lutero; Livre arbítrio; Vontade humana.

1 Doutorando no programa de Filosofia pela Pontifícia Universidade Católica de São Paulo. Professor do Centro Universitário Nove de Julho.

E-mail: sidneid@.com.br

Rev. Filos., v. 18 n.23, p. 89-103, jul./dez. 2006 
Abstract

Erasmus of Rotterdam and Martin Luther debate the notion of human free will. Is rational will free? Or does human nature possess no autonomy being its will solely dependant on God's? The religious crisis of the XVI century discusses the reform of the Official Roman Church and proposes disruption to the culture born through the first Fathers of the Church at the end of Antiquity. The religious world is rebuilt through dialogs and conflicts between orthodoxy and the dissidents.Christian Humanism and the Protestant Reform, Erasmus and Luther, agree to one point: "Heaven is not for sale". Nevertheless, what at a first glance might seem to set them closer, will enlarge their distance, indeed, when the subject comes to the evident disregard of the Reformers to Church Tradition. As opposed to his adversary, Luther, Erasmus turns to Antiquity and accepts, whether understanding it or not, what the Church had elaborated over many centuries of religious culture. Hence, the discussion over human free will leads to - and, at the same time is led by - the schism of the Christian dogma, to the separation between Philosophy and Theology and to the beginning of Modern Age.

Keywords: Erasmus; Luther; Free will of humanity.

O texto Sobre Livre Arbítrio de Erasmo de Rotterdam teve sua primeira publicação em setembro de 1524, na feira de Frankfurt. Considerado um dos grandes acontecimentos editoriais da época, como centro da discussão da intelectualidade, não deixou de ser episódio restrito unicamente àqueles que pertenciam à Igreja, que viviam próximos das discussões acerca da fé, do pecado, da graça e do livre arbítrio da vontade humana, não provocando, portanto, pela sua importância, o debate das grandes massas. Mesmo não sendo reconhecido pela grande maioria, a discussão entre Erasmo e Lutero marcou uma nova orientação religiosa dividindo a cristandade do século XVI em facções, principalmente entre os que tomavam partido da teologia de Lutero em oposição à Igreja Oficial de Roma.

Erasmo escreve o Livre Arbítrio como alusão às assertivas de Lutero depois da disputa teológica em Leipzig, ocorrida nos meses de junho e julho em 1519, entre o Dr. João Eck, principal teólogo da Universidade de Ingolstadt, defensor da Igreja Católica Romana e renomado debatedor, e André Karlstadt, na época deão da Faculdade de Teologia de Wittenberg e colega de Lutero. Discussões acaloradas que dividiram

Rev. Filos., v. 18 n.23, p. 89-103, jul./dez. 2006 
o dogma cristão, mas que na opinião de Erasmo eram mais fatigantes do que propriamente importantes para fazer aparecer a verdade concernente à questão do papado (origem, fundamento, autoridade) e, sobretudo, às questões sobre a livre iniciativa da vontade.

Já nas primeiras linhas de sua obra acerca do livre arbítrio, Erasmo destaca as dificuldades, que não lhe parecem poucas, para tratar de um assunto tão complicado:

Entre as dificuldades presentes em grande número dentro das Santas Letras, não há labininto mais inextricável do que aquele acerca do livre arbítrio. Pois, outrora, o filósofo, depois também o teólogo, tão antigo quanto moderno, exerceu de maneira impressionante seu espírito, porém, segundo minha opinião, com mais embaraço do que proveito ${ }^{2}$ (ERASMUS, 1910, p. 1)

Lutero, por outro lado, comenta o debate em Leipzig condenando o livre arbítrio. 0 monge de Witenberg se opõe à livre iniciativa da vontade humana afirmando que

... o livre arbítrio é meramente passivo em todo o seu fazer - que se chama querer - e que é em vão que se palra a distinção dos sofistas de que o ato bom é todo de Deus, não, porém, totalmente. Porque, de fato, é todo e totalmente de Deus, visto que a vontade só é tracionada, arrastada e movida pela graça. Essa tração que se transmite aos membros e às forças tanto da alma como do corpo é sua atividade e nenhuma outra, assim como é meramente passiva a tração de uma serra que corta a madeira, visto ser originada pelo serrador; ela também em nada contribui para sua tração; no entanto, sendo tracionada, corta a madeira, mais impelida do que impelindo. Esse ato de serrar é denominado sua obra pelo serrador, embora a serra meramente sofra a ação do serrador (LUTERO, 1987, p. 367-368).

Os elementos conceituais da discussão entre Lutero e Erasmo, que se dará de maneira mais efetiva alguns anos depois do debate em Leipzig, já estão lançados. O humanista cristão reage e com moderação

2 "Inter difficultates, quae non paucae occurrunt in divinis literis, vix ullus labyrinthus inexplicabior quam de libero arbitrio. Nam haec materia iam olim philosophorum, deinde theologorum etiam, tum veterum, tum recentium ingenia mirum in modum exercuit, sed maiore, sicut opinor, negotio quam fructu" (ERASMUS, 1910, p. 1).

Rev. Filos., v. 18 n.23, p. 89-103, jul./dez. 2006 
parte em defesa do livre arbítrio humano e da tradição dos primeiros padres, questionando o caráter intempestivo de Lutero e a sua maneira de interpretar as passagens do Antigo e do Novo Testamento. O que está em jogo nessa discussão é a defesa da dignidade humana, da alma como imagem e semelhança de Deus, da tradição da Igreja Oficial de Roma, da contribuição intelectual e cultural que foi feita pelos primeiros teólogos, entre eles gregos e latinos, passando por uma lista de autores escolásticos.

...também da doutrina cristã, a qual defenderam nas escrituras, e redigiram seu testemunho com sangue, os quais estão entre os gregos: Orígenes, Basílio, Crisóstomo, Cirilo, João Damasceno, Teófilo, entre os latinos: Tertuliano, Cipriano, Arnóbio, Hilário, Ambrosio, Jeronimo, Agostinho, não contando entre eles Tomas, Scot, Durando, Capreolos, Gabriel, Egidio, Gregório, Alexandre. ${ }^{3}$ (ERASMUS,1910, p. 12-13)

A primeira edição do Servo Arbítrio se deu um ano depois da publicação do Livre Arbítrio. Lutero não deixa sem respostas o que considera absurdos apresentados pelo seu opositor acerca dos preceitos cristãos. $\mathrm{O}$ monge de Witenberg não suporta 0 racionalismo moderado de Erasmo e sua maneira polida de falar de temas tão sérios, porque envolvem a crença dos mais humildes acerca da fé, da graça, da liberdade, da salvação e das obras. As passagens escriturísticas, para Lutero, não deixam dúvidas quanto ao seu conteúdo, pois, na sua opinião, tanto o Antigo quanto o Novo Testamento são tão claros que não necessitam de interpretações como pretende o seu adversário.

Portanto tu e os sofistas (Lutero se refere a Erasmo e a Patrologia da Igreja) tratai de apresentar um único mistério qualquer que ainda esteja abstruso nas Escrituras. Todavia, o fato de muitas coisas terem permanecido abstrusas para muitas pessoas não se deve à obscuridade da Escritura, mas à cegueira ou indolência delas, que não tratam de ver a verdade claríssima, como diz Paulo a respeito dos judeus em 2 Cońntios 4 (sc. 3.14): 'O véu permanece sobre o coração deles.' (LUTERO, 1993, p. 25)

3 “...etiam doctrinae Christi, quam scriptis defenderant, sanguine suo testimonium reddiderunt, quales sunt apud Graecos Orígenes, Basilius, Chrysostomus, Cyrillus, Joannes Damascenus, Theophylactus; apud Latinos Tertullianus, Cyprianus, Arnobius, Hilarius, Ambrosius, Heronymus, Augustinus, ne recenseam interim Thomas, Scotos, Durandos, Capreolos,Gabrieles, Aegidios, Gregorios, Alexandros..."3 (ERASMUS, 1910, p. 12-13).

Rev. Filos., v. 18 n.23, p. 89-103, jul./dez. 2006 
Ambos só estavam de acordo sobre o seguinte: o céu não está à venda. ${ }^{4}$ Essa postura atrai a simpatia de Lutero perante Erasmo. No entanto, quanto mais o reformador procura sua simpatia, mais se distancia a possibilidade de ambos caminharem juntos defendendo a mesma causa. Quanto às críticas, a Igreja Oficial de Roma no que diz respeito à corrupção que se instalara em seu interior no final da Idade Média, ambos estavam de acordo, mas o que Erasmo não admitia era romper peremptoriamente com a tradição da Igreja de Roma e não reconhecer a santidade dos primeiros padres. De uma coisa o humanista estava certo: a tradição intelectual e cultural que envolve a formação do pensamento cristão no final da Antigüidade deve ser mantida.

A teologia dos primeiros padres influenciada pelo estoicismo até os meados do século III d.C. considera o homem como parte de uma idéia da totalidade, sendo esta representada pela idéia de Deus. O movimento, a energia própria da natureza (Cosmo), é compreendida pelos estóicos como providência, isto é, como Deus presente na natureza. $\mathrm{O}$ homem como criatura pertence a essa totalidade, dotado de alma racional, como semente divina e dádiva do Criador.

A providência pode se considerar de duas maneiras, conforme se aplica ou a ordem geral do mundo, as leis dos fenômenos, ou ao curso dos acontecimentos humanos e ao destino de cada homem em particular. E, em primeiro lugar Providência é o sentido que todos os deuses tomam do mundo. O que é na verdade a natureza? Para o estoicismo enfim, ela não é nada que pareça, por exemplo, à matéria inerte, uma massa de terra ou pedregulho, mas de preferência um desejo organizado que se vai declarando, progredindo dentro do animal ou da árvore. Ora, tudo o que existe dentro da natureza é regido por ela. Assim, portanto, tudo o que é "natural" é governado por Deus-mundo." (FESTUGIÈRE, O.P”5 , 1932, p. 8-7)

4 “... le ciel n'est pas à vendre! Pour le reste, ils n’ont guère d'affinités.” (HALKIN, 1987, p. 218).

5 "La providence peut se considérer de deux manières, selon qu'on l'applique ou à l'ordre général du monde, aux lois des phénomènes, ou bien au cours des événements humains et à la destinée de chaque homme en particulier. Et, tout d'abord, la Providence est le soin que prennent du monde tous les dieux. Qu'est-ce en effet que la nature? Pour le stoïcisme enfin, ce n'est rien qui ressemble, par exemple, à de la matière inerte, motte de terre ou caillou, mais plutôt um dessein concerté qui se va déclarant, progressant, dans l'animal ou dans l'arbre. Or, tout ce qui est dans la nature est regi par elle. Ainsi donc, tout ce qui est "naturel" est gouverné par le Dieu-monde..." (FESTUGIĖRE,1932)

Rev. Filos., v. 18 n.23, p. 89-103, jul./dez. 2006 
Há uma concepção de natureza humana na teologia e filosofia de Erasmo que é condizente com o médio platonismo constituído pela assimilação e síntese que os primeiros padres fizeram da filosofia de Platão e dos Estóicos no final da Antigüidade. O conceito de teologia da imagem elaborado pelo cristianismo afirma que o elemento divino em nós é a imagem imperfeita, mas verdadeira, da divindade, que recebemos de Deus. Esta imagem é o logos como semente do Pai, quer dizer, o Espírito de Deus em nós (SPANNEUT, 1957).

O homem interior feito à imagem de Deus não é a alma ou o nous enquanto elemento específico da construção humana que, conforme a tradição platônica, é invisível, incorruptível, incorporal e imortal. Pois estas qualidades caracterizam essencialmente o Verbo, ele próprio imagem verdadeira de Deus, o Pai. Nós devemos compreender as qualidades de invisibilidade, de incorruptibilidade, de incorporeidade e de imortalidade não como qualidades naturais do homem feito à imagem de Deus, mas, de preferência, como dons divinos de Deus-Logos ao homem feito a Sua imagem. O homem interior não é a alma ou a inteligência enquanto elemento específico da composição humana, mas o homem que recebe dentro de seu elemento o mais alto, a incorporeidade, a incorruptibilidade, a invisibilidade e a imortalidade de Deus-Logos ${ }^{6}$ (LEKKAS, G., 2001, p. 41-41).

O que se pretende demonstrar diferente da filosofia platônica é que a alma não é constitutiva da natureza humana como estatuto ontológico próprio de cada ser, mas uma revelação, um dom de Deus, que potencializa a natureza humana para adquirir a perfeição e se tornar divina.

6 “Ainsi l’homme intérieur n'est pas l'âme ou le nous em tant qu'élément spécifique de la construction humaine, qui, selon la tradition platonicienne, est invisible, incorruptible, incorporel et immortel. Ces qualités caractérisent essentiellement le Verbe lui-même em tant qu'image véritable de Dieu lê Père. Nous devons donc comprendre les qualités de l'invisibilité, de l'incorrutibilité, de l'incorporéité et de l'immortalité non em tant que qulités naturelles de l'homme "fait à l'image de Dieu", mais plutôt em tant que dons divins du Dieu-Logos à l'homme fait à Son image.L'homme intérieur n'est donc pas l'âme ou l'intelligence em tant qu'élément spécifique de la composition humaine, mais l'homme qui reçoit dans son élément le plus haut l'incorporéité, l'incorruptibilité, l'invisibilité, et l'immortalité du Dieu-Logos"' (LEKKAS, 2001, p. 40-41). 
Erasmo ratifica a teologia da imagem nos dizendo que a razão ou logos como dádiva de Deus ao homem é sua parte hegemônica que o faz tender naturalmente em direção ao Criador. A natureza humana, para o humanista cristão não está totalmente separada de Deus, porque cumpre naturalmente seu movimento de retorno ao mundo superior e divino. A criatura para Erasmo é meio humana e divina. Deus como Logos divino está dentro da criatura como atribuição de sua imagem dentro da alma humana.

Mas de qualquer maneira, nestes que carecem da graça (a respeito da graça particular), a razão foi obscurecida, mas não destruída; assim é provável que a mesma força da vontade não tivesse sido destruída completamente, porém se torna incapaz de fazer o bem. A razão está para a alma assim como o olho está para o corpo. Ela é a parte iluminada pela luz natural, inscrita em todos, embora não na mesma medida, como quem tem presente no espírito: Nós fomos marcados pela luz de tua face Senhor. (Sl 4, 7) Em parte também os preceitos divinos e as sagradas escrituras ao dizer do nosso salmista: Tua palavra, uma luz para os meus pés (Sl 118, 105). ${ }^{7}$ (ERASMUS,1910, p. 22-23).

A cosmologia erasmiana considera o homem parte integrante da totalidade. Deus, homem e mundo estão integrados pelo movimento dinâmico que a natureza possui. O homem participa da divindade porque faz parte integrante da energia cósmica, divina, produzida por Deus. ${ }^{8}$

O cristianismo elaborado no final da Antigüidade nasce fortemente marcado pelo estoicismo quando concebe a natureza como um todo harmônico, divino, em constante movimento que participa da natureza interior do homem. Dentro desse ambiente religioso antigo, Justino nos diz que a semente do logos é inata, dentro de todo o gênero humano (SPANNEUT, 1957). Nesse movimento contínuo em que as naturezas divina e humana participam uma da outra, imbricadas entre si, a razão

7 "Quemadmodum autem in his, qui gratia carent (de peculiari loquor) ratio fuit obscurata, non exstincta, ita probalile est in iisdem voluntatis vim non prosus exstinctam fuisse, sed ad nonesta infefficacem esse factam. Quod oculus est corpori, hoc ratio est animo. Ea partim illustratur luce nativa, quae ínsita est omnibus, licet non pari mensura, de quo meminit psalmus: Signatum est super nos lúmen vultur tui, domine, partim praeceptis divinis ac literis sacris, quemadmodum dicit psaltes noster: Lucerna pedibus méis verbum tuum." (ERASMUS, 1910, p.22-23).

8 Como dizia Paulo: Idem dominus ominium Rm 1,12 (o mesmo Senhor de todos).

Rev. Filos., v. 18 n.23, p. 89-103, jul./dez. 2006 
humana tende a se voltar em direção à totalidade, superior e divina. A contribuição do platonismo no final da Antigüidade aparece quando se admite uma idéia de Bem localizado no mundo superior, invisível, que, no entanto, quando cristianizado pelos primeiros padres, Deus não só está para lá do mundo das idéias platônicas, mas também dentro de cada um de nós.

O livre arbítrio é a vontade racional que, por ser racional, participa da dignidade da imagem que o homem possui de Deus. A natureza humana racional tende para o bem. $O$ mal não existe, é o não-ser da vontade; neste sentido, a razão cessa seu movimento natural e deixa de existir. A alma, quando se fixa no mundo material, não realiza o seu movimento em direção ao mundo superior e divino e não participa da totalidade.

contudo, nem toda paixão do homem é came, mas é, como se diz, alma, ou espírito que se lança para o bem. Chamam esta parte da alma, como razão ou hegemônica sendo esta, a principal, a superior, sem a qual nenhum filósofo se inclinou para o bem. Ensinaram mil vezes o homem enfrentar a morte antes que admita a infâmia, ainda que nós soubéssemos o futuro, e que o homem ignorasse que Deus perdoa, posto que freqüentemente corrupta a razão julga mal. ${ }^{9}$ (ERASMUS,1910, p. 63)

Erasmo considera a razão como o piloto da alma, assim como para o platonismo. A vontade localizada na alma, quando decide em favor do mundo material, se constitui como vontade má. A vontade racional é livre e, sendo assim, realiza seu movimento originário em direção ao mundo superior e divino.

Para Lutero a razão é estulta e ignorante, e Erasmo só fala monstruosidades para defender sua causa. A Diatribe pretende defender 0 livre arbítrio como se existisse uma vontade racional que pudesse nos conduzir à salvação. De que valeria os sofrimentos de Cristo? Então quer dizer - questiona o reformador - que a razão é superior ao sofrimento na Cruz por que passou o Filho de Deus?

9 "Nec tamen omnis affectus hominis est caro, sed est, qui dicitur anima, est, qui dicitur spiritus, quo nitimur ad honesta, quam partem animi rationem vocant aut hegemonico id est principalem, nisi forte in philosophis nullus fuit ad honesta nixus, qui docuerunt milies oppetendam morte citius, quam advmittendam turpitudinem, etiamsi sciremus futurum, ut et ignorarenete homines et deus ignosceret, quamquam saepe corrupta ratio male jidicat”. (ERASMUS, 1910, p.63).

Rev. Filos., v. 18 n.23, p. 89-103, jul./dez. 2006 
Lutero rompe com a teologia da imagem e a tradição dos primeiros padres. $\mathrm{O}$ reformador reconhece a santidade dos padres da Igreja Oficial de Roma por amor e não por direito de reconhecê-los como santos pela fé:

Chamo-os de santos e os tenho por tais, chamo-os de Igreja de Deus e julgo que o são, mas faço-o pela regra do amor, não pela regra da fé, isto é, do amor que pensa o melhor a respeito de qualquer um, não é suspeitoso, tudo crê e presume coisas boas acerca dos próximos e chama de santo a qualquer pessoa batizada. E não há perigo se 0 amor erra, pois é próprio dele ser enganado, já que está exposto a todos os usos e abusos de todos, é servo geral dos bons, maus, fiéis, infiéis, verazes e falazes. A fé, porém, não chama ninguém de santo a menos que tenha sido declarado santo pelo juízo divino, pois é próprio da fé não se enganar. (LUTERO, 1993, p. 64).

A teologia da imagem foi substituída pela teologia da cruz. ${ }^{10}$ Esta última não reconhece a alma como semente divina, como dádiva de Deus aos homens. Sem a dignidade da imagem cabe à criatura reconhecer sua natureza como pecadora, insuficiente, e sua pequenez diante da grandeza de Deus. O cristão deve desesperar-se, não que a consciência de sua miséria represente uma boa obra aos olhos de Deus, mesmo porque desconhecemos completamente suas vontades. Não há obras moralmente boas capazes de nos reconciliar com Deus, mesmo porque somos incapazes de fazer o bem por nossas próprias forças. A razão que guia a alma em direção ao bem é uma estultice, o que resta à criatura é só sofrimento, lamentação e humilhação.

Erasmo nos diz acerca da noção de livre arbítrio: "Por livre arbítrio pensamos este emprego da força da vontade humana pela qual o homem pode se aplicar ao que conduz à salvação eterna, ou da mesma se afastar."11 Definitivamente essa é a passagem do texto que Lutero não tolera. A definição que Erasmo desenvolve acerca da noção de livre

10 "Não se pode designar condignamente de teólogo quem enxerga as coisas invisíveis de Deus compreendendo-as por intermédio daquelas que estão feitas; mas sim quem compreende as cosas visíveis e posteriores de Deus enxergando-as pelos sofrimentos e pela cruz." (LUTERO, 1987).

11 "Porro liberum arbitrium hoc loco sentimus vim humanae voluntatis, qua se possit homo applicare ad ea, quae perducunt ad aeternam salutem, aut ab issdem aveter." (ERASMUS, 1910, p.19).

Rev. Filos., v. 18 n.23, p. 89-103, jul./dez. 2006 
arbítrio está completamente equivocada porque não há possibilidade de a vontade se aplicar ou se desviar de alguma coisa. Essa autonomia da vontade é uma ilusão. A vontade não é racional, não é livre e nem possui discernimento no que concerne à salvação eterna. Erasmo brinca com coisas sérias. O racionalismo de Erasmo é inadmissível para a compreensão das Sagradas Escrituras. A salvação não concerne ao homem, mas exclusivamente a Deus.

Creio (Lutero), porém, que as coisas que levam à salvação eterna são as palavras e as obras de Deus, que são oferecidas à vontade humana para que a elas se aplique ou delas se afaste. De 'palavras de Deus', porém, chamo tanto a lei quanto o Evangelho. Pela lei se exigem obras; pelo Evangelho, a fé. Pois não há outra coisa que leve tanto à graça de Deus quanto à salvação eterna senão a palavra e a obra de Deus. Para Erasmo, porém, o livre arbítrio não só se move por sua própria força, mas também se aplica às coisas que são eternas, isto é, que lhe são incompreensíveis. É um definidor (Erasmo) inteiramente novo e inaudito do livre arbítrio, que deixa longe atrás de si os filósofos, os pelagianos, os sofistas e todos os demais (LUTERO, 1993, p. 76-77).

A vontade só faz o mal porque não possui condições de realizar o contrário. A graça se sobrepõe à vontade, porque esta sem o socorro divino não é capaz de se voltar para o bem. A criatura está separada de Deus, e não há nada que possa fazer para melhorar sua condição de pecadora. Necessariamente a natureza humana só faz o mal. Não há uma via de mão dupla como se pudéssemos imaginar uma alternância da vontade, ora fazendo o bem ou o mal. A via é sempre de mão única, isto é, a vontade só sabe fazer o mal.

Para responder aos ataques de Lutero contra a livre iniciativa da vontade, Erasmo retoma a citação de Paulo (Rm 5,2): "Sabemos que 0 julgamento de Deus se exerce segundo a verdade contra aqueles que praticam tais ações". ${ }^{12}$ Erasmo prossegue: "Ouves a ação, ouves o julgamento conforme a verdade. Onde a mera necessidade? Onde a vontade não é senão passiva?'13 $\mathrm{O}$ que o humanista nos diz é que onde há neces-

12 Bíblia de Jerusalém.

13 "Audis actionem, audis iudicium secundum veritatem. Ubi mera necessitas? Ubi voluntas nihil aliud quam patiens?" (ERASMUS, 1910, p.42).

Rev. Filos., v. 18 n.23, p. 89-103, jul./dez. 2006 
sidade não existem boas ações, não há mérito em praticar obras moralmente boas se a vontade é exclusivamente paciente e não ativa. Qual a responsabilidade sobre as conseqüências de nossas decisões? Onde há necessidade não há liberdade e nem méritos.

A graça como um dom imerecido de Deus não suprime a iniciativa da vontade:

Não faltam entretanto quem considere imensa a bondade de Deus dizendo tão somente progredir o homem de boas ações, como quem se prepara para a graça e a misericórdia de Deus com respeito ao que se impõe, embora exista quem negue que esta misericórdia possa acontecer sem possuir a graça particular. ${ }^{14}$ (ERASMUS, 1910, p. 29)

Erasmo não desconsidera os méritos e as boas ações em detrimento da graça divina. Os méritos, a vida solidária, o controle sobre as paixões nos fazem ser agradáveis a Deus.

Portanto, visto que por muito tempo se afastaram para longe de Pelágio, muitos atribuíram a graça, e quase nada ao livre arbítrio, contudo não o abolindo completamente: negam o poder do homem conquistar o bem sem a graça peculiar, negam o poder de iniciar, negam o poder de progredir, negam o poder de conseguir sem a principal e perpétua proteção da graça divina. Desta sentença se percebe como suficientemente provável que se omita do homem a obra e o esforço ainda que não se omite, o que dela se atribuía aos homens... ${ }^{15}$ (ERASMUS,1910, p. 30).

A conduta moral, a relação com o próximo é inseparável da teologia de Erasmo. O que exaspera seu adversário além de seu racionalismo moderado é a sua compreensão do que seja a fé. $\mathrm{O}$ humanista não

14 "Nec desunt tamen, qui considerata immensa dei bonitae dicant hactenus hominem proficere huiusmodi benefactis, ut praeparetur ad gratim ac dei misericordiam erga se provocet, quamquam sunt, qui negent haec etiam fieri posse sine gratia peculiari." (ERASMUS, 1910, p.29).

15 "Ergo, qui longissime fugiunt a Pelagio, plurimum tribuunt gratiae, libero arbitrio pene nihil nec tamen in totum tollunt: negant hominem posse velle bonum sine gratia peculiari, negant posse incipere, negant posse progredi, negant posse perficere sine principali perpetuoque gratiae divinae praesidio. Horum sententia satis videtur probabilis, quod relinquat homini studium et conatum et tamen non relinquit, quod suis ascribat viribus." (Idem, p. 30).

Rev. Filos., v. 18 n.23, p. 89-103, jul./dez. 2006 
só admite a fé como uma certeza das verdades e promessas da Escritura, mas também lhe confere uma importância existencial. A fé é uma virtude incoativa por excelência e não uma letra morta de um texto sagrado. A fé engendra as obras e uma convivência pacífica e tolerante entre os povos. A certeza da salvação passa pelo caminho que deve ser trilhado em direção ao bem. Deus, Filho e Espírito Santo, hipóstases correspondentes à elaboração da Santíssima Trindade que se projetam na criatura por meio das virtudes.

O caminho em direção ao bem com consciência e responsabilidade se conjuga à liberdade de decisões e escolhas. "...Erasmo se mostra em geral mais atento em sublinhar as conseqüências morais do ato de fé do que em escrutar seu conteúdo noético."16 Somos livres para decidir entre o bem e o mal cientes de que a conduta moral preza pelas decisões em direção ao bem e nunca o contrário. Quando decidimos em direção ao melhor optamos por estarmos próximos de Deus.

Para Lutero, a consciência não se conjuga com liberdade, mas com sofrimento e humilhação. Em seu texto: Debate acerca do Homem, Lutero nos diz que a razão após o pecado está entregue ao poder do diabo (LUTERO, 1992). Em sua outra obra: Acerca da Justificação, o reformador afirma que o mal é inato e inerente a nós, fazendo-nos réus da morte eterna; ele dura enquanto vivermos aqui e pode ser chamado de hábito inato (LUTERO, 1992). Erasmo ignora essas afirmações. O humanista cristão admite que os méritos e as obras não se sobrepõem à fé, que é possível conjugar a graça e as boas obras. Que a relação entre a graça divina e as ações humanas não são excludentes.

Lutero (1987), em Debate sobre a Teologia Escolástica, afirma: "É verdade que o ser humano, sendo árvore má, não pode senão querer e fazer o mal". Mais adiante nesse mesmo texto ele manifesta sua concepção de natureza: "Está errado que, por natureza, a vontade possa conformar-se ao ditame correto".

Erasmo e Lutero são modernos e tradicionalistas, dependendo da maneira como são considerados. Erasmo retoma a tradição cultural do cristianismo primitivo se manifestando contra a apropriação que a Igreja Oficial de Roma fez dessa cultura como mecanismo de poder fo-

16 "Érasme se montre em general plus attentif à souligner les conséquences morales de l'acte de foi qu'à em scruter le contenu noétique..." Érasme. Dictionnaire établi par Claude Blum, André Godin, Jean-Claude Margolin et Daniel Ménager. Paris: Ed. Robert Laffont, 1992.

Rev. Filos., v. 18 n.23, p. 89-103, jul./dez. 2006 
mentando as guerras. O médio platonismo do final da Antigüidade e a síntese operada pelos primeiros padres entre filosofia grega e cristianismo estão presentes em sua teologia marcada pela predominância de uma concepção de natureza humana racional, que possui uma vontade racional e livre, como representação do divino no humano.

Quando observamos o lugar que a alma racional ocupa em sua teologia, o que viria séculos mais tarde a ser denominado como sujeito do conhecimento, e sua maneira de louvar a dignidade humana, Erasmo se apresenta como um humanista e moderno. Mas, por outro lado, o humanista cristão também é um tradicionalista e conservador quando nos diz que aceita a Igreja de Roma compreendendo ou não o que ela ordena. O humanista cristão se curva às decisões da Igreja no que concerne à distinção entre o verdadeiro e o falso para interpretar os Livros Sagrados e rejeita a conduta de Lutero frente à tradição. Nesse momento, poderíamos considerá-lo um cético, posição que irritava em demasia seu adversário. Lutero se pergunta como é possível conjugar a fé com ceticismo?

E vou não atraído pelas exigências, como facilmente nas sentenças dos cépticos plebeus sem partidos, onde quer que através das Divinas Escrituras e inviolável autoridade da Igreja que decreta e fixa, a quem meu julgamento submeto com alegria, mesmo compreendendo o que prescreverá ou não. ${ }^{17}$ (ERASMUS, 1910, p. 3)

Lutero por sua vez também é um moderno quando rompe com a ortodoxia e a tradição do cristianismo. Inicia a Reforma questionando os arautos do cristianismo e a autoridade da Igreja Oficial de Roma. Interpreta as Sagradas Escrituras, levado por uma persuasão interior. Comenta as passagens escriturísticas porque são claras e estão disponíveis a todos.

Na opinião dos reformadores, era a consciência ou a luz interior: como saber qual luz interior tinha razão? Para os calvinistas, tinha razão àquela que vinha do Santo Espírito ou era guiada por ele. Mas quem

17 "Et adeo non delector assertionibus, ut facile in Scepticorum sententiam pedibus discessurus sim, ubicumque per divinarum scripturarum inviolabilem auctoritatem et ecclesiae decreta leceat, quibus meum sensum ubique libens submitto, sive assequor, quod praescribit, sive no assequor." ( ERASMUS, 1910, p.03).

Rev. Filos., v. 18 n.23, p. 89-103, jul./dez. 2006 
possuía uma tal luz interior? Como fazer a diferença entre a ilusão e a iluminação verdadeira? Os reformadores se remetiam aparentemente às suas opiniões pessoais: Calvino não duvidava que Calvino recebeu a iluminação verdadeira. ${ }^{18}$ (POPKIN, R.H, 1979, p. 47)

Por outro lado, o reformador rejeita a vontade racional, a alma como dignidade que a natureza humana possui como dádiva de Deus, a autonomia da vontade em decidir qual a melhor direção a seguir, mesmo secundada pela graça. Para o reformador a razão é subsumida completamente pelo Santo Espírito e a certeza de que está interpretando as Escrituras corretamente advém da fé na iluminação verdadeira. O que poderia parecer moderno manifesta-se como ortodoxo e até certo ponto dogmático.

Lutero e Erasmo contribuíram cada um a seu modo para o advento da modernidade na primeira metade do século XVI. Modernos ou ortodoxos, suas posições filosóficas e teológicas abriram novos caminhos para a compreensão do homem, do mundo e de Deus. O Cristianismo não fora mais o mesmo. Os questionamentos que se seguiram após a discussão acerca do livre arbítrio da vontade representaram para os Humanistas Cristãos a descoberta da razão liberada da crosta interpretativa medieval desenvolvida pela escolástica, mas, ao mesmo tempo, para os dissidentes, se no campo político houve uma mudança significativa porque romperam com a hierarquia clerical oficial, no domínio da moral, paradoxalmente, corroboraram com Igreja Oficial de Roma no que se refere à permanência de uma moral austera, de uma razão completamente obscurecida e corrompida pelo pecado, incapaz de fazer o bem.

18 "A en croire les réformateurs, c'était la conscience ou la lumière intérieure: comment savoir quelle lumière intérieure avait raison? Pour les calvinistes, avait raison celle qui venait du Saint-Esprit ou était guidée par lui. Mais qui possédait une telle lumière intérieure? Comment faire la différence entre l'illusion et l'illunination véritable? Les réformateurs s'en remettaient apparemment à leurs opinions personnelles: ainsi Calvin ne doutait-il pas que Calvin reçut l'illumination véritable." (POPKIN, 1979).

Rev. Filos., v. 18 n.23, p. 89-103, jul./dez. 2006 
Referências

ERASMUS, D. De Libero Abitrio: DIATRIBIs sive Collatio. Leipzig: Georg Böhme, 1910.

FESTUGIÈRE, O. P. L'idéal religieux des Grecs et l'Évangile. Paris: Gabalda, 1932.

HALKIN, L. E. Erasme. Paris: Fayard, 1987.

LEKKAS, G. Liberté et progres chez Origène. Bélgica: Brepols, 2001

LUTERO, M. Comentários de Lutero sobre suas Teses Debatidas em Leipzig. Tradução de Ilson Kayser. Rio Grande do Sul: Sinodal, 1897.

. Da Vontade Cativa. Tradução de Luís Marcos Sander, Luís Henrique Dreher e Ilson Kayser. Rio Grande do Sul: Sinodal, 1993,

. O Debate de Heidelberg. Tradução de Walter O. Schlupp. Rio Grande do Sul: Sinodal, 1987.

. Debate acerca do homem. Tradução de Johannes Friedrich Hasenack. Rio Grande do Sul: Sinodal, 1992.

. Acerca da justificação. Tradução de Luis Henrique Dreher. Rio Grande do Sul: Sinodal, 1992.

. Debate sobre a teologia escolástica. Tradução de Walter 0 . Schlupp. Rio Grande do Sul: Sinodal, 1987.

MARGOLIN, J. Dictionnaire. Paris: Robert Laffont, 1992.

POPKIN, R. H. Histoire du scepticisme d'Érasme a Spinoza. Paris: PUF. 1979.

SPANNEUT, M. Le Stoicisme des Péres de l'Église. Paris: Du Seuil, 1957.

Recebido em/Received in: 28/08/2006 Aprovado em/Approved in: 15/09/2006

Rev. Filos., v. 18 n.23, p. 89-103, jul./dez. 2006 